\title{
Stereotactic amygdalotomy in the management of severe aggressive behavioral disorders
}

\author{
Maria Mpakopoulou, M.D., Haralambos Gatos, M.D., Alexandros Brotis, M.D., \\ Konstantinos N. Paterakis, M.D., Ph.D., and Kostas N. Fountas, M.D., Ph.D.
}

Department of Neurosurgery, University Hospital of Larissa, School of Medicine, University of Thessaly, Larissa, Greece

\begin{abstract}
Object. Stereotactic amygdalotomy has been utilized as a surgical treatment for severe aggressive behavioral disorders. Several clinical studies have been reported since the first description of the procedure. In the current study, the authors reviewed the literature and evaluated the surgical results, neuropsychological outcome, and complication rate in patients who had undergone stereotactic amygdalotomy for severe aggressive behavioral disorders.

Methods. The PubMed database was searched using the following terms: "amygdalotomy," "amygdalectomy," "amygdaloidectomy," "psychosurgery," "aggressive disorder," and "behavioral disorder." Clinical series with more than 5 patients undergoing stereotactic amygdalotomy for aggressive or other behavioral disorders were included in this review. The surgical technique, anatomical target, improvement in psychiatric symptomatology, postoperative employment and social rehabilitation, postoperative neurocognitive function, procedure-related complications, and long-term follow-up were evaluated.

Results. Thirteen clinical studies met our inclusion criteria. Reported postoperative improvement in aggressive behavior varied between 33 and 100\%. Procedure-related complication rates ranged from 0 to $42 \%$, whereas the mortality rate was as high as $3.8 \%$. In the majority of the reviewed clinical series, the performance of stereotactic amygdalotomy did not compromise a patient's learning, language, and intellectual capabilities. The long-term follow-up, although very limited, revealed that initially observed improvement was maintained in most cases.

Conclusions. Stereotactic amygdalotomy can be considered a valid surgical treatment option for carefully selected patients with medically refractory aggressive behavioral disorders. Recent advances in imaging and stereotactic navigation can further improve outcome and minimize the complication rate associated with this psychosurgical procedure. (DOI: 10.3171/FOC/2008/25/7/E6)
\end{abstract}

\section{KEY WORDS • aggressive behavioral disorder • amygdalotomy • complication • outcome • stereotaxy}

$\mathrm{T}$ HE hippocampus and medial temporal structures have been considered major components of the limbic lobe since its original description by Broca in $1878 .{ }^{6}$ From the beginning it was postulated that structures of the limbic lobe were not exclusively or even primarily olfactory in function but instead were implicated in the formation of emotions and behavior. ${ }^{23}$ Friedrich Goltz ${ }^{11}$ first reported in 1892 that the removal of the temporal lobe in dogs made them calmer and more tame. Later, Klüver and Bucy, ${ }^{19}$ Thomson and Walker, ${ }^{42}$ and Schreiner and Kling ${ }^{35-37}$ also demonstrated in monkeys and cats that a temporal lobectomy and amygdalectomy had a taming effect. Terzian and $\mathrm{Ore}^{41}$ confirmed these findings by showing the same taming effect in humans following temporal cortical structure and amygdala removal.

Over the next decades, there was increasing evidence that the amygdaloid nucleus was a dominant component of

Abbreviations used in this paper: $\mathrm{EEG}=$ electroencephalography; $\mathrm{PEG}=$ pneumoencephalography. the basolateral limbic circuit and actively involved in the development of aggressive behavior. ${ }^{23} \mathrm{Ursin}^{43}$ demonstrated in experimental animal studies that electrical stimulation of the amygdala could provoke organized affective reactions. Based on these observations, Narabayashi et al..$^{32}$ described a clinical series of 60 patients who had undergone stereotactic amygdalotomy for severe aggressive behavior. Since that initial report, there have been $>500$ reported cases of stereotactic amygdalotomy for various behavioral disturbances and epilepsy, with varying results. ${ }^{10,12,13,15,18,20,21,26,27,30,31,39}$ Different surgical approaches have involved various stereotactic devices and modalities for amygdaloid nucleus destruction, such as the injection of alcohol, oil, kaolin, or wax; cryoprobe lesioning; mechanical destruction; diathermy loop; and radiofrequency lesioning. ${ }^{1,9,12,14,16,20,25,38}$ During the past 3 decades, however, advances in neuropharmacology along with the practical banning of psychosurgery have led to a significant decrease in the number of amygdalotomies performed around the world. 
In the current study, we reviewed the pertinent literature while focusing on the role of stereotactic amygdalotomy in the management of aggressive behavioral disorders, the surgical technique of stereotactic amygdalotomy, procedure-related complications, and clinical and neuropsychological outcomes.

\section{Methods}

An extensive search of the PubMed medical database was performed using the terms "amygdalotomy," "amygdalectomy," "amygdaloidectomy," "psychosurgery," "aggressive disorder," and "behavioral disorder." Retrieved articles were carefully screened for series of patients undergoing stereotactic amygdalotomy for either a behavioral disorder alone or behavioral and epilepsy disorders combined. Clinical series with $>5$ patients undergoing stereotactic amygdalotomy for aggressive or other behavioral disorders were included in our review, whereas miniseries (4 patients) and case reports were excluded. Clinical series of patients undergoing stereotactic amygdalotomy exclusively for epilepsy without concomitant behavioral symptomatology were also excluded from our study. We attempted to identify the repetition of clinical series reported in different journals; only the original clinical series were included in our study. Note, however, that this task was not easy, and the reader must be aware of potential redundancies in the reported data.

We evaluated preoperative imaging and surgical planning, the use or exclusion of additional intraoperative electrophysiological monitoring, the surgical technique, the exact anatomical target, observed procedure-related complications, the reported response of preoperative psychiatric symptomatology, postoperative employment and social rehabilitation, postoperative neurocognitive function, and long-term follow-up data whenever available.

\section{Results}

Eighteen clinical series met our inclusion criteria; however, only 13 were finally included in our review, because the remaining 5 studies consisted of presenting cases that had been included in a previous series. The number of patients, indication for undergoing stereotactic amygdalotomy, surgical technique, observed complications, and immediate and long-term outcome rates are summarized in Table 1.

In their original clinical series consisting of 60 patients with marked behavior disturbances (such as hyperexcitability, assaultive behavior, or violent aggressiveness) treated with bilateral stereotactic amygdalotomy, Narabayashi and colleagues ${ }^{32}$ reported that $51(85 \%)$ of 60 patients demonstrated a marked reduction in emotional excitability and normalization of social behavior and adaptation postoperatively. These authors routinely performed the surgical procedures in patients in a state of general endotracheal anesthesia. Pneumoencephalography was used for anatomical target localization, whereas intraoperative depth EEG and olfactory stimulation were utilized for physiological confirmation of the target. A stereotactic apparatus devised by the authors was used in all of their cases. The lateral group of amygdaloid nuclei was routinely targeted in their series, and a lesion $8-10 \mathrm{~mm}$ in diameter was created by injecting $0.6-0.8 \mathrm{ml}$ of a mixture of lipiodol, oil, and wax. In a follow-up study, ${ }^{33}$ the authors reported that follow-up data were available for only 40 patients from the original series. They found that 27 of these patients $(67.5 \%)$ continued to have marked and relatively satisfactory improvement in behavior, maintaining the calming and taming effect of bilateral stereotactic amygdalotomy $\sim 3$ years afterward. They also found that younger patients (between 5 and 13 years of age) had better long-term outcomes than older patients. In a later follow-up study, Narabayashi ${ }^{30}$ reported that among patients undergoing bilateral stereotactic amygdalotomy, those who most benefited from treatment of their behavioral and emotional disturbances also experienced improvement in any coexistent epileptic traits.

During this same period, in 1966, Chitanondh ${ }^{7}$ described a stereotactic amygdalotomy involving a slightly different technique. The procedure was performed after applying a local anesthetic. A bur hole was placed $3 \mathrm{~cm}$ lateral to the midline and $1 \mathrm{~cm}$ anterior to the interaural line. Target localization was performed with contrast ventriculography. The target was placed in the medial half of the amygdaloid nuclear complex. Verification of the anatomical target was achieved by performing EEG and amygdalography via a stereotactically inserted needle. Chitanondh reported on a series of 7 patients: 3 with olfactory seizures, 2 with schizophrenia including olfactory hallucinations, 1 with posttraumatic personality disorder with olfactory hallucinations, and 1 with an obsessive-compulsive habit of smelling. Interestingly, he reported significant postoperative behavioral improvement and resolution of preoperative EEG abnormalities in all of the patients. Lesions were formed by injecting $1 \mathrm{ml}$ of a mixture of olive oil, white bee wax, and strong iodized oil, and these stereotactic lesions served as a means of mechanical blocking.

Also in 1966, Heimburger and associates ${ }^{13}$ described a series of 25 patients undergoing stereotactic amygdalotomy for behavioral abnormalities, epilepsy, and major depression. Procedures were performed after applying a local anesthetic while carefully tracking the emotional and neurological responses of the patient throughout the procedure. This study differed from others in that the operative technique was slightly different and target localization was solely anatomical. The use of PEG or ventriculography with positive contrast medium allowed for target localization, whereas a cryoprobe was used to create lesions. The cryoprobe was stereotactically introduced through a 3-mm twist drill skull opening into the amygdaloid nucleus complex. The anatomical target averaged $2.0 \mathrm{~cm}$ lateral to the midline, $1.0 \mathrm{~cm}$ below the intercommissural line, and $45 \%$ posterior to the anterior commissure along the intercommissural line. The center of the lesion was placed in the anteromedial part of the amygdala. The tip of the cryoprobe was gradually cooled over 5 minutes to $\left(120^{\circ} \mathrm{C}\right.$, and this temperature was maintained for 3 minutes. A second lesion was usually produced using the same technique. Later, however, this method was abandoned, and the cryoprobecreated lesions were replaced with mechanical lesions, which were more precise from an anatomical standpoint and had a smaller volume. ${ }^{39}$ Heimburger and colleagues ${ }^{13}$ reported that $35 \%$ of their patients became free of any behavioral abnormalities and that $45 \%$ of them had significant improvement. 
Stereotactic amygdalotomy for aggressive behavioral disorders

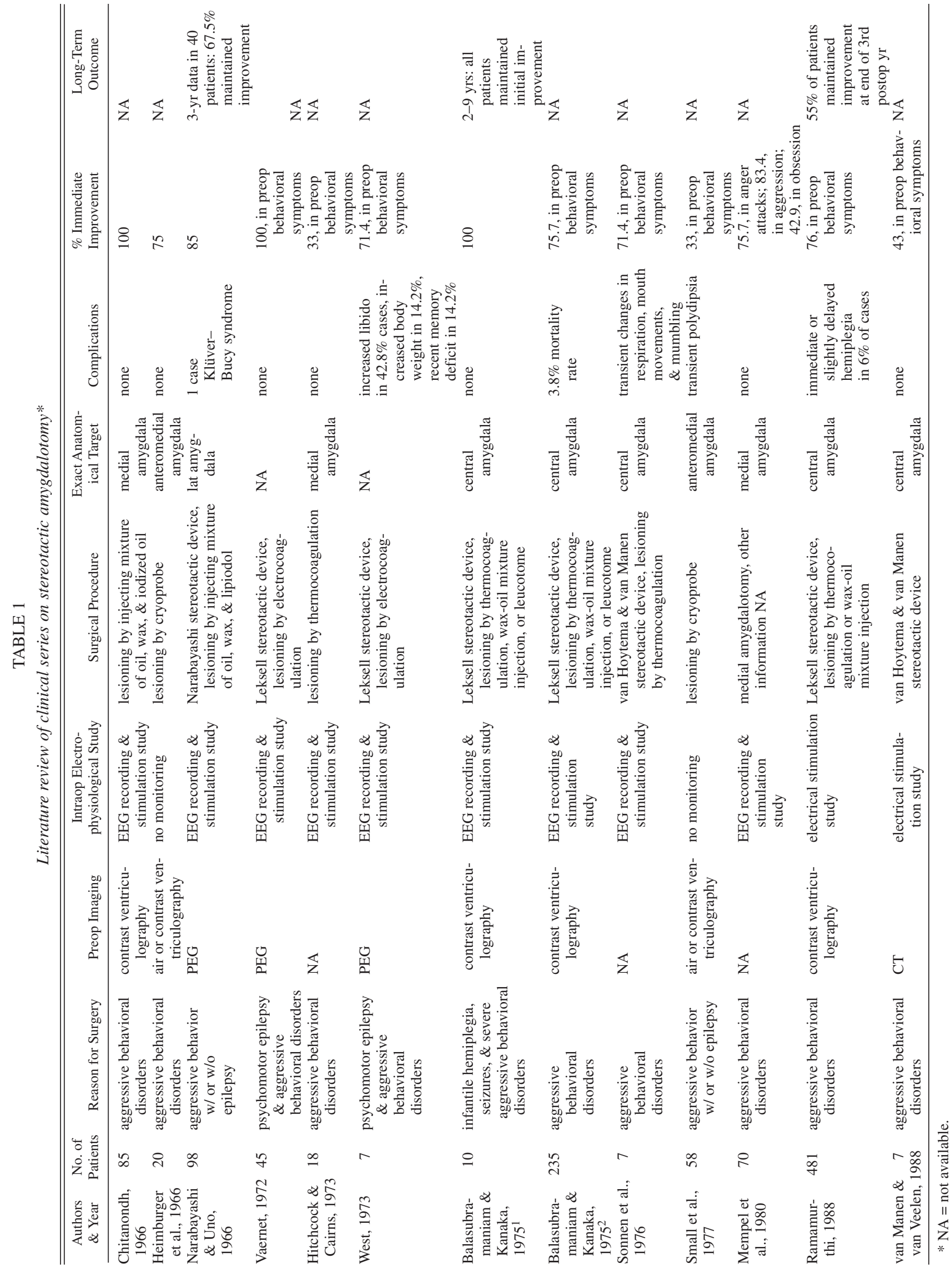


Similarly, Balasubramaniam and Ramamurthi ${ }^{4}$ reported on a large clinical series of 100 patients who had undergone bilateral stereotactic amygdalotomy for assaultive, hyperkinetic, destructive, self-destructive, or pyromaniac behavior. The surgical procedure was routinely performed after inducing a state of general endotracheal anesthesia., ${ }^{3,5}$ The researchers used PEG or contrast ventriculography to preoperatively define the anatomical target, whereas intraoperative EEG with or without olfactory stimulation was performed in the majority of cases. They used the Leksell stereotactic system with a slight modification consisting of a central hole in the original carrier to facilitate the entrance of the lesioning device. The center of the amygdaloid nucleus was always targeted in their patients, and 9 adjacent lesions were placed using either a diathermy 8-mm electrode for thermal lesioning or a Bertrand loop for mechanical destruction of the amygdala. Results showed that $6 \%$ of the patients studied had marked behavior improvement with no episodes of violence even without medication, whereas another 33\% demonstrated significant improvement while remaining on their preoperative medications and exhibiting only occasional violent outbursts. Another $36 \%$ of the patients experienced some improvement in their symptoms. ${ }^{4}$ Unfortunately, there was no report on the duration of the follow-up period in their study. The authors did find that patients with behavioral disorders associated with epilepsy had better outcomes than those with disorders linked to encephalitis.

In 1973 Hitchcock and Cairns ${ }^{14}$ reported on 18 patients with hyperactive, destructive, and rebellious behavioral disorders. Most patients in their study also had a history of epilepsy. The authors performed bilateral stereotactic amygdalotomies after applying a local anesthetic or inducing general anesthesia, depending on the patient's willingness to cooperate during the procedure. They preferred a transtemporal approach instead of the previously described transfrontal method, because they believed that a direct transtemporal route might be both shorter and safer. They obtained physiological confirmation of the anatomical target via electrical stimulation in cases treated after applying a local anesthetic. A $3 \times 1.8$-mm depth electrode (Radionics) was stereotactically introduced, and electrical stimulation was applied to verify the target. The stimulation parameters were as follows: voltage $1-10 \mathrm{~V}$, frequency 5$100 \mathrm{~Hz}$, and pulse width $1 \mathrm{msec}$. The target was centered on the medial group of the amygdaloid nucleus complex, although the intention was to destroy the whole amygdala. Postoperative improvement in violent and destructive behavior in $27.7 \%$ of patients was reported.

Similarly, Small et al. ${ }^{39}$ described a series of 58 patients, of whom 12 had solely behavior disorders and 46 had seizure and behavior disorders for which they underwent bilateral stereotactic amygdalotomy. Procedures were performed in all 58 patients after the application of a local anesthetic. The surgical technique was the same as that described by Heimburger et al. ${ }^{13}$ whereas the anatomical target was centered in the anteromedial part of the amygdaloid nucleus. ${ }^{39}$ Intraoperative EEG monitoring was available in most cases. Approximately one-third of the patients who had undergone the operation primarily for behavioral disorders experienced behavioral improvement (mean follow-up time 6 years), whereas $40 \%$ in the combined disorder group had behavioral improvement. The authors also noted a trend among patients with psychomotor attacks: those who were younger fared slightly better than older patients. Similarly, Mempel et al. ${ }^{27}$ reported clinical improvement in behavior disturbances in $60-70 \%$ of 70 patients with epilepsy and behavioral disturbances.

\section{Discussion}

Since Narabayashi's 1961 introduction of stereotactic amygdalotomy for the treatment of severe aggressive behavior, numerous outcome studies have been published. ${ }^{1-5,7,12-15,24,26,32-34,39,40,45,46}$ It must be emphasized that a comparison of the results of these series is meaningless given the nonhomogenous populations studied, the differences in the surgical technique applied, and the significantly varying outcome criteria. It has been demonstrated that the amygdala in humans consists of 23 distinct subnuclei, which have been identified. ${ }^{14,17}$ In the literature focused on this subject, there has been some discussion about the optimal anatomical target in cases of stereotactic amygdalotomy. In initial descriptions of the procedure, ${ }^{8,32}$ the lateral group of amygdaloid nuclei, which is better developed than the medial group, was targeted. In contrast, other clinical investigators $7,13,14,27,39$ have targeted the anteromedial group of amygdaloid nuclei, and the central region of the amygdaloid nucleus has been targeted in only a limited number of clinical series. ${ }^{1,2,34,40,45}$

Physiological confirmation of the anatomical target, by using intraoperative EEG monitoring alone or EEG monitoring together with olfactory stimulation by ether, has been performed in the majority of published clinical series. ${ }^{1,2,7,14,27,33,34,40,44-46}$ However, Heimburger et al. ${ }^{13}$ and Small et al. ${ }^{39}$ performed their procedures without electrophysiological monitoring. Recent advances in neuroanesthesia may allow intraoperative electrical stimulation studies in awake patients undergoing stereotactic amygdalotomy not only to confirm the accuracy of the anatomical target, but also to define the exact part of the amygdaloid nuclei complex that must be lesioned. Careful observation of a patient's response to intraoperative electrical stimulation may well guide the surgeon in selecting the most appropriate amygdaloid nuclei subgroup as a target.

In regard to the observed mortality rate associated with stereotactic amygdalotomy, only a study by Balasubramanian and Kanaka ${ }^{2}$ revealed a 3.8\% mortality rate. The occurrence of procedure-related complications has varied significantly among published clinical series. ${ }^{1-5,7,12-15,24,27,32-34,39}$, 40,44-46 Hitchcock and Cairns ${ }^{14}$ reported no procedure-related complications and no postoperative impairment in the intellectual functioning of their patients. Similarly, Balasubramaniam and Ramamurthi ${ }^{4}$ reported no postoperative cases of Klüver-Bucy syndrome, memory deficits, or hypersexuality. In another clinical series of 50 patients, Balasubramaniam et al. ${ }^{5}$ reported 1 case of transient ptosis, 10 cases of transient hemiplegia (which was attributed to the proximity of the crus to the created lesion), and 1 case of prolonged postoperative unconsciousness, irregular temperature, and convulsions in a patient with postencephalitic aggressive behavioral disturbance. In their original series Narabayashi and colleagues ${ }^{32}$ encountered no cases of postoperative Klüver-Bucy syndrome; in their expanded series, ${ }^{33}$ however, 1 patient (1.0\%) had partial Klüver-Bucy 
syndrome 1 week after surgery, with symptoms consisting of unsteadiness, oral tendency, hypersexuality, and relative hypermetamorphosis. This patient's symptoms lasted for 2 months but were finally controlled with high doses of chlorpromazine.

Numerous animal electrophysiological studies in monkeys have shown that visual discrimination learning is increasingly impaired after combined amygdala-hippocampal lesioning compared with that following destruction of the hippocampus alone. ${ }^{22,28,49}$ Furthermore, it has been demonstrated that monkeys with combined amygdala-hippocampal ablations are severely impaired in both tactile and visual versions of a memory task, whereas monkeys that undergo hippocampectomy alone show no learning deficits in either modality. 22,29 Young and associates ${ }^{47,48}$ have described a case of face-processing impairment following a partial bilateral amygdalotomy; however, Lee at al. ${ }^{22}$ have reported a patient whose attention and memory were preserved after undergoing bilateral stereotactic amygdalotomy. Lee and colleagues concluded that bilateral amygdalotomy does not impair a patient's ability to associate an object from one sensory modality to another. Furthermore, Luczywek and Mempel ${ }^{24}$ reported that in a series of 46 patients with epilepsy who had undergone bilateral mediodorsal amygdalotomy, the majority had significant IQ improvement postoperatively. This improvement was even more prominent among patients with preoperative IQs $>90$. Their findings further support the impression that amygdalotomy does not compromise learning, language, and intellectual capabilities of patients. ${ }^{21,22}$

Advances in neuropharmacology during the last $3 \mathrm{dec}-$ ades, along with the skepticism regarding the surgical treatment of psychiatric disorders, have led to the abandonment of stereotactic amygdalotomy in treating patients with severe aggression or self-mutilation disorders. Note, however, that certain cases of violent behavioral disorders that do not respond to any other treatment modality might benefit from stereotactic amygdalotomy. Medically refractory cases of aggressive, assaultive behavior or of self-mutilation resistant to appropriate pharmacological or behavioral treatment may improve with stereotactic amygdalotomy. The introduction of high-field MR imaging units in routine clinical practice, in which the amygdaloid nuclei can be nicely identified, and the development of frameless neuronavigational systems of high accuracy can make stereotactic amygdalotomy an appealing treatment option in these patients. A team of experienced psychiatrists and a functional neurosurgeon very familiar with psychosurgical procedures should select appropriate surgical candidates. It cannot be overemphasized that this procedure should be considered only in extreme cases after exhausting all other therapeutic options and only when the patient and his or her family are fully aware of the potential outcome and risks of the procedure.

\section{Conclusions}

Since its introduction by Narabayashi, stereotactic amygdalotomy has evolved into a more accurate and precise stereotactic procedure. However, the development of psychopharmacology and the growing skepticism of the international medical community regarding psychosurgery have resulted in the minimal utilization and almost total disregard for the procedure as well as many other psychosurgical procedures. Nonetheless, continuing improvement in neuroimaging along with the evolution of neuronavigational and stereotactic systems may well increase the application of stereotactic amygdalotomy in treating carefully selected patients suffering from severe, medically refractory aggressive behavioral disorders.

\section{References}

1. Balasubramaniam V, Kanaka TS: Amygdalotomy and hypothalamotomy-a comparative study. Confin Neurol 37:195-201, 1975

2. Balasubramaniam V, Kanaka TS: Why hemispherectomy? Appl Neurophysiol 38:197-205, 1975

3. Balasubramaniam V, Ramamurthi B: Stereotaxic amygdalotomy. Proc Aust Assoc Neurol 5:277-278, 1968

4. Balasubramaniam V, Ramamurthi B: Stereotaxic amygdalotomy in behavior disorders. Confin Neurol 32:367-373, 1970

5. Balasubramaniam V, Ramamurthi B, Jagannathan K, Kalyanaraman S: Stereotaxic amygdalotomy. Neurology India 15:119 122, 1967

6. Broca P: Anatomie compare des enconvolutions cerebrales. Le grand lobe limbique et la scissure limbique dans la serie des mammiferes. Rev Anthrop 1:385-498, 1878

7. Chitanondh H: Stereotaxic amygdalotomy in the treatment of olfactory seizures and psychiatric disorders with olfactory hallucination. Confin Neurol 27:181-196, 1966

8. Crosby EC, Humphrey T: Studies of the vertebrate telencephalon II. The nuclear pattern of the olfactory nucleus, tuberculum olfactorium and the amygdaloid complex in adult man. J Comp Neurol 74:309-352, 1941

9. Fountas KN, Smith JR: Historical evolution of stereotactic amygdalotomy for the management of severe aggression. J Neurosurg 106: 710-713, 2007

10. Fountas KN, Smith JR, Lee GP: Bilateral stereotactic amygdalotomy for self-mutilation disorder. Case report and review of the literature. Stereotact Funct Neurosurg 85:121-128, 2007

11. Goltz F: Der Hund ohne Grosshirn. Siebente Abhandlung über die Verrichtungen des Grosshirns. Pflügers Archiv 51:570-614, 1892

12. Heimburger RF, Small IF, Small JG, Milstein V, Moore D: Stereotactic amygdalotomy for convulsive and behavioral disorders. Long-term follow-up study. Appl Neurophysiol 41:43-51, 1978

13. Heimburger RF, Whitlock CC, Kalsbeck JE: Stereotaxic amygdalotomy for epilepsy with aggressive behavior. JAMA 198: 741-745, 1966

14. Hitchcock E, Cairns V: Amygdalotomy. Postgrad Med J 49:894-904, 1973

15. Hood TW, Siegfried J, Wieser HG: The role of stereotactic amygdalotomy in the treatment of temporal lobe epilepsy associated with behavioral disorders. Appl Neurophysiol 46:19-25, 1983

16. Jelasic F: Relation of the lateral part of the amygdala to pain. Confin Neurol 27:53-55, 1966

17. Johnston JB: Further contributions to the study of the evolution of the forebrain. J Comp Neurol 35:337-481, 1923

18. Kiloh LG, Gye RS, Rushworth RG, Bell DS, White RT: Stereotactic amygdaloidotomy for aggressive behavior. J Neurol Neurosurg Psychiatry 37:437-444, 1974

19. Klüver H, Bucy PC: Preliminary analysis of function of the temporal lobes in monkeys. Arch Neurol Psychiatr 42:979-1000, 1939

20. Lee GP, Arena JG, Meador KJ, Smith JR, Loring DW, Flanigin HF: Changes in autonomic responsiveness following bilateral amygdalotomy in humans. Neuropsychiatry Neuropsychol Behav Neurol 1:119-129, 1988 
21. Lee GP, Bechara A, Adolphs R, Arena J, Meador KJ, Loring DW, et al: Clinical and physiological effects of stereotaxic bilateral amygdalotomy for intractable aggression. J Neuropsychiatry Clin Neurosci 10:413-420, 1998

22. Lee GP, Meador KJ, Smith JR, Loring DW, Flanigin HF: Preserved crossmodal association following bilateral amygdalotomy in man. Int J Neurosci 40:47-55, 1988

23. Livingston KE, Escobar A: The continuing evolution of the limbic system concept, in Hitchcock E, Laitinen L, Vaernet K (eds): Psychosurgery. Springfield, Ill: Charles C Thomas, 1972, pp 25-33

24. Luczywek E, Mempel E: Stereotactic amygdalotomy in the light of neuropsychological investigations. Acta Neurochir Suppl 23: 221-223, 1976

25. Mark VH, Sweet WH, Ervin FR: The effects of amygdalotomy on violent behavior in patients with temporal lobe epilepsy, in Hitchcock E, Laitinen L, Vaernet K (eds): Psychosurgery. Springfield, Ill: Charles C Thomas, 1972, pp 139-155

26. Mempel E: The effect of partial amygdalectomy on emotional disturbances and epileptic seizures. Pol Med J 10:968-974, 1971

27. Mempel E, Witkiewicz B, Stadnicki R, Luczywek E, Kucinski L, Pawlowski G, et al: The effect of medial amygdalotomy and anterior hippocampotomy on behavior and seizures in epileptic patients. Acta Neurochir Suppl 30:161-167, 1980

28. Mishkin M: Memory in monkeys severely impaired by combined but not by separate removal of amygdala and hippocampus. Nature 273:297-298, 1978

29. Murray EA, Mishkin M: Severe tactual as well as visual memory deficits follow combined removal of the amygdala and hippocampus in monkeys. J Neurosci 4:2565-2580, 1984

30. Narabayashi H: From experiences of medial amygdalotomy on epileptics. Acta Neurochir Suppl 30:75-81, 1980

31. Narabayashi H: Lessons from amygdaloid surgery in long-term observation. Acta Neurochir Suppl 23:241-245, 1976

32. Narabayashi H, Nagao T, Saito Y, Yoshida M, Nagahata M: Stereotaxic amygdalotomy for behavior disorders. Arch Neurol 9:1-16, 1963

33. Narabayashi H, Uno M: Long range results of stereotaxic amygdalotomy for behavior disorders. Confin Neurol 27:168-171, 1966

34. Ramamurthi B: Stereotactic operation in behavior disorders. Amygdalotomy and hypothalamotomy. Acta Neurochir (Wien) 44:152-157, 1988

35. Schreiner L, Kling A: Behavioral changes following rhinencepalic injury in cat. J Neurophysiol 16:643-659, 1953

36. Schreiner L, Kling A: Effects of castration on hypersexual behav- ior induced by rhinencephalic injury in cat. AMA Arch Neurol Psychiatry 72:180-186, 1954

37. Schreiner L, Kling A: Rhinencephalon and behavior. Am J Physiol 184:486-490, 1956

38. Siegfried J, Reichenbach W: Personal experiences in the stereotaxic surgery of psychiatric patients, in Umbach W (ed): Special Topics in Stereotaxis. Stuttgart: Hippokrates Verlag, 1971, pp 106-111

39. Small IF, Heimburger RF, Small JG, Milstein V, Moore DF: Follow-up of stereotaxic amygdalotomy for seizure and behavior disorders. Biol Psychiatry 12:401-411, 1977

40. Sonnen AEH, Manen JV, van Dijk B: Results of amygdalotomy and fornicotomy in temporal lobe epilepsy and behavior disorders. Acta Neurochir Suppl 23:215-219, 1976

41. Terzian H, Ore GD: Syndrome of Klüver and Bucy reproduced in man by bilateral removal of the temporal lobes. Neurology 5: 373-380, 1955

42. Thomson AF, Walker AE: Behavioral alterations following lesions of the medial surface of the temporal lobe. Folia Psychiatr Neurol Neurochir Neerl 53:444-452, 1950

43. Ursin H: The temporal lobe substrate of fear and anger. A review of recent stimulation and ablation studies in animals and humans. Acta Psychiatr Scand 35:378-396, 1960

44. Vaernet K: Stereotaxic amygdalotomy in temporal lobe epilepsy. Confin Neurol 34:176-180, 1972

45. van Manen J, van Veelen CW: Experiences in psycho-surgery in the Netherlands. Acta Neurochir Suppl 44:167-169, 1988

46. West KA: Treatment of psychomotor epilepsy with stereotaxic amygdalotomy. Ann Clin Res 5:60-64, 1973

47. Young AW, Aggleton JP, Hellawell DJ, Johnson M, Broks P, Hanley JR: Face processing impairments after amygdalotomy. Brain 118:15-24, 1995

48. Young AW, Hellawell DJ, Van De Wal C, Johnson M: Facial expression processing after amygdalotomy. Neuropsychologia 34:31-39, 1996

49. Zola-Morgan S, Squire LR, Mishkin M: The neuroanatomy of amnesia: Amygdala-hippocampus versus temporal stem. Science 218:1337-1339, 1982

Manuscript submitted March 31, 2008.

Sources of support: none reported.

Accepted April 24, 2008.

Address correspondence to: Kostas N. Fountas, M.D., Ph.D., Labrou Katsoni Street, Terpsithea 41500, Larissa, Greece. email: fountas@med.uth.gr. 